\title{
THE SUPPOSED “TIGER-CAT" OF QUEENSLAND
}

By Maurice Burton, D.Sc.

The evidence for the existence of a large marsupial " tigercat " in Queensland, Australia, is meagre, and this, together with an absence of tangible relics, makes for a lack of credence. On the other hand, one may go further and suggest that even this little evidence has been accorded an unjustified obscurity. There is, therefore, this much excuse for returning to it, if only to bring the few fragments together for those who may wish to reflect on them.

The first published record appears to have been communicated to a meeting of the Zoological Society of London in $\mathbf{1 8 7 1}$ and published in the Proceedings for that year (pp. 629-630). From Mr. Sclater's remarks then, it would appear that rumours of the existence of this animal had been sufficiently strong to cause notice to be taken. Troughton, in his Furred Animals of Australia (1946), and Frank Lane later, in his book Nature Parade, both quote from this, but both give an inadequate reference. In addition, by the brevity of the quotation each gives an imperfect picture of the account presented by Sclater. It is therefore worth requoting in full.

"Mr. Sclater called the attention of the meeting to the reported existence in Northern Queensland of an undescribed animal of about the size of a Dingo (Canis dingo), of which no specimen had yet been obtained by naturalists. In reply to some inquiries on this subject lately addressed to Mr. Brinsley G. Sheridan, Police Magistrate of Cardwell, Rockingham Bay, Queensland, Mr. Sclater has received the following letter, dated 2nd August, 1871 :-

" 'Sir,-I fear you must have misunderstood Mr. Arthur Scott about my son having been attacked by some unknown ferocious animal in the bush. It was simply this. One evening, strolling along a path close to the shore of Rockingham Bay, a small terrier, my son's companion, took a scent up from a piece of scrub near the beach, and followed, barking furiously, towards the coast-range westwards. My boy (thirteen years of age, but an old bushman, who would put half those described in novels to the blush) followed and found in the long grass, about half a mile from the spot the scent was first taken up, an animal described by himself as follows: "It was lying camped in the long grass and was as big as a native Dog; its face was round like that of a Cat, it had a long tail, and its 
body was striped from the ribs under the belly with yellow and black. My Dog flew at it, but it could throw him. When they were together I fired my pistol at its head; the blood came. The animal then ran up a leaning tree, and the Dog barked at it. It then got savage and rushed down the tree at the Dog and then at me. I got frightened and came home."

" "It was just dark when the boy came home in a high state of excitement and told me the story. From inquiry I find that this is not the first time a similar animal has been seen in this neighbourhood. Tracks of a sort of Tiger have been seen in Dalrymple's Gap by people camping there, and Mr. Reginald Uhr, now Police Magistrate at St. George, whilst one of the native mounted police officers in this district, saw the same animal my'son describes. The country is so sparsely populated, and the jungles (or, as we call them here, " scrubs") so dense and so little known, that I have no doubt that animals of this kind exist in considerable numbers, the abundance of food and their timidity preventing our more intimate knowledge of their habits. I shall be most happy to send you, should it be my good fortune to drop across one of them, its skin and skeleton. I only regretted, as my poor boy did, that he had not my revolver, as he says he stood, when it was fighting with the Dog, at less than a yard from the animal."

The following year (see Proc. Zool. Soc. London, 1872, p. 355) Gould read an extract from a letter addressed to the Secretary by Mr. Walter T. Scott, C.M.Z.S., dated Vale of Herbert, Cardwell, Queensland, 4th December, 1871. Mr. Scott wrote as follows of the supposed "Native Tiger" of Queensland, concerning which Mr. Sclater had previously communicated the evidence given by Mr. Sheridan (see P.Z.S., 1871, p. 629) :-

"As to the Tiger, I am inclined to think there really is some large carnivorous animal as yet undescribed in this neighbourhood. A Mr. Hull, Licensed Surveyor, was lately at work with a party of five men, surveying on the Murray and Mackay rivers, north of Cardwell. They were lying in their tents one night between eight and nine o'clock when they were all startled by a loud roar close to the tents. They seized their guns and carefully reconnoitred; but the animal had departed. In the morning they found the tracks of the unknown visitor, of which Mr. Hull took the measurements and a rough sketch. I send you part of a leaf of Mr. Hull's field-book, containing the original sketchand also his drawing of the track, of the natural size. Mr. Hull assures me that the drawing was a very faithful one, the soft 
ground having taken the impression with all its details. I have also examined some of the men who were with Mr. Hull. They all tell the same story, and say they heard the animal three nights in succession.

"I think that I have already mentioned to you that a bullockdriver of ours, as long ago as 1864, came in one day with a story that he had seen a Tiger; but as he was a notorious liar we did not believe a word of it at the time. Yet it is possible he may really have seen the same animal, which must I think, from its claws, be allied to the Tasmanian Thylacine (Thylacinus cynocephalus)."

Troughton, in the work already referred to, lists other testimony, as follows, but gives no references, so that one can but quote his words. George Sharp, a well-known naturalistcollector, had a passing sight of something "larger and darker than the Tasmanian Tiger, with the stripes showing very distinctly". It vanished before he could raise his gun. A more detailed description comes from Ion L. Idriess. "Up here in York Peninsula we have a tiger-cat that stands as high as a hefty, medium-sized dog. His body is lithe and sleek and beautifully striped in black and grey. His pads are armed with lancelike claws of great tearing strength. His ears are sharp and pricked, and his head is shaped like that of a tiger. My introduction to this beauty was one day when I heard a series of snarls from the long huffalo-grass skirting a swamp. On peering through the grass I saw a full-grown kangaroo, backed up against a tree, the flesh of one leg torn clear from the bone. A streak of black and grey shot towards the 'roo's' throat, then seemed to twist in the air, and the kangaroo slid to earth with the entrails literally torn out. In my surprise I incautiously rustled the grass, and the great cat ceased the warm feast that he had promptly started upon, stood perfectly still over his victim, and for ten seconds returned me gaze for gaze. Then the skin wrinkled back from the nostrils, white fangs gleamed and a low growl issued from his throat. I went backwards and lost no time in getting out of the entangling grass. The next brute I saw was dead, and beside him was my much-prized staghound, also dead. This dog had been trained from puppyhood in tackling wild boars, and his strength and courage were known by all the prospectors over the country. The cat had come fossicking round my camp on the Alice River."

Troughton's final account is from the Brisbane Courier (date not given), communicated by G. de Tournoeur, who in company with P. B. Scougall was riding from Munna Creek toward Tiaro 
township. Their horses shied and they dismounted, to see a large "cat", twenty yards away, astride a dead calf, glaring defiance and emitting a growling whine. It was dusk and raining but they judged the beast's size to be that of a mastiff. It was " a dirty fawn colour, with a whitish belly and broad blackish tiger stripes. The head was round with rather prominent lynxlike ears", a tail reaching to the ground and large pads.

In his own book Troughton comments : "The creature probably lives in the thick forests which man seldom penetrates, or in which he makes so much noise in getting through that the more wary animal is seldom seen." And again, " . . there seems no doubt that a large striped marsupial-cat haunts the tangled forests of North Queensland."

It is possible that nothing more may be heard of the alleged "tiger-cat", that it may go down, or has gone down, before human settlement, or in competition with the wild dog and it is now extinct. In any case, to the zoologist, with no more evidence of its existence than that to hand, any discussion on the possibility of such a beast having formed part of the Australian fauna is somewhat academic. It is, however, not without profit to examine the arguments for and against the testimony of eye-witnesses.

The first obvious comparison is with the Thylacine. It is significant that all reports of the "tiger-cat" suggest a likeness to it. There are, however, differences which would seem to preclude the eye-witnesses having been deceived by the actual presence of the Thylacine in Northern Queensland, or having been influenced by a knowledge, however remote, of the appearance of that animal. The only drawing of its track could not have been that of a Thylacine, unless it is a woefully bad representation of the track as seen. On the other hand, a strong argument against the existence of the "cat" is that whereas traces of the Thylacine have been found sub-fossil, none has been seen of the "tiger-cat".

It is, however, worth drawing attention to the attempts in recent years to locate the Thylacine, which is known to exist. Fleay (Vict. Nat. Melbourne, 63, 1946, pp. 129, 154, 174) has described his persistent and well-organized attempts to see or trap the Thylacine, which failed completely. Yet he is able to include at the end of his account the news that tracks were subsequently seen by other people. This merely means, as any field naturalist is aware, that it is possible to search diligently and for a long time the territory of a known species and yet never obtain a sight of it. There are plenty of places in England, for example, 
where badgers are plentiful yet the local inhabitants are unaware of it. Moreover, a visiting naturalist may try for a long time without success to have a sight of them. Yet in these same localities motorists often report seeing badgers in their headlights. If for motorists with headlights we read a police magistrate, a police magistrate's son, a licensed surveyor and others,

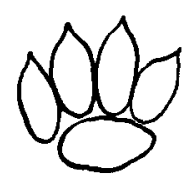

A

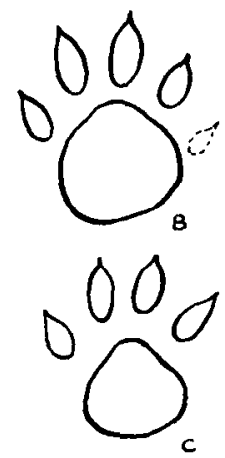

Attempted comparison of the footprints of the supposed tiger-cat of Queensland with those of the thylacine.

A. A copy of the footprint of the "tiger-cat" published in the Proceedings of the Zoological Society of London, 1872. Size not given.

$B$. and $C$. The tracks of the thylacine (B. fore-foot, $C$. hindfoot) drawn from examination of the feet of a museum skin. While they may not truly represent thylacine tracks, they are sufficient to show a marked divergence in the proportions of pad to toe between them and the alleged print of a tiger-cat. The dew claw is marked in dotted lines as it is impossible to tell whether or not it would have shown in the footprint.

and for heavily settled England we read Queensland, with a scanty population and forests little explored, it is not surprising if no zoologist has seen a " tiger-cat " and no camera has recorded it. It is merely another instance of random observation giving the only chance of success.

Before leaving the comparison with the Thylacine there is yet one other, more convincing, argument. Anyone comparing the marsupial fauna of Australia with the placental mammals in other parts of the world must be struck with the parallel between their ecological grouping. In both there are grazing, browsing, arboreal, burrowing and the many other types necessary to a balanced ecology. Among the marsupials predators are represented by the Thylacine, which is the counterpart of the wolf, and a few smaller animals are also present, but the counterpart of the big cats is missing. Theoretically there must have existed in pre-settled Australia the ecological niche for a tiger-cat. 
It is interesting to review the names of large or medium-sized mammals, many of which are now household words, and the dates on which the animals themselves were made known to science (although some were reported much earlier). The Aye Aye, of Madagascar, was first reported in 1780 and not seen again until 1860. Plagiodontia aedium (a rodent), of San Domingo, was first recorded in 1836, and not again seen until 1948. Marco Polo's Deer was first seen by Marco Polo, and not made known to science until 1838. The Golden Hamster, of which one specimen was seen in Syria in 1839, was not re-discovered until 1930. The Gorilla, Pere David's Deer and the Giant Panda, discovered in 1847, 1866 and 1869 respectively ; the Gerenuk, known to the Ancient Egyptians, but not to science until 1878; the Okapi (1901), the Giant Forest Hog (1904), both of Central Africa, the Mountain Nyala, of Abyssinia (1908), the Golden Takin of Western China (1910) and Osbornictus piscivora of Central Africa (1919) were all large enough to be seen yet escaped detection. Finally, Plagiodontia hylaeum, also of San Domingo, was not made known to science until as recently as 1948. (Incidentally the Abominable Snowman is still at large.)

Two other mammals deserve a notice. The Victorian Genet, of the Ituri Forest, is practically unknown except for skins collected by natives. And Schomburghk's Deer has never been seen in the wild by Europeans. Probably nothing would have been known of it, apart from the random observations of licensed surveyors, police magistrates and the like, had the antlers, in velvet, not been prized for their alleged medicinal value. As it is, although the antlers have appeared as an article of commerce in the Siamese markets, only one complete and mounted specimen is known.

The tiger-cat of Queensland may yet appear in the flesh or the bone. 